\title{
Application of Pneumatic Soft Mechanism to a Human Friendly Robot
}

\author{
Toshiro NORITSUGU, Daisuke SASAKI and Masahiro TAKAIWA \\ Faculty of Engineering, Okayama University \\ 3-1-1 Tsushimanaka , Okayama , 700-8530 Japan \\ E-mail : toshiro@sys.okayama-u.ac.jp \\ daisuke@mcrlab.sys.okayama-u.ac.jp
}

\begin{abstract}
When robots work together with a human or contact with a human body directly in such as a medical welfare åeld, in order to avoid an accident from crash and so on, a çexibility is required for the robot.

The purpose of this study is to realize a safe mechanism for a human-friendly robot. The soft mechanism comprises a soft actuator and a soft sensor. The soft actuator and soft sensor are made of a silicone rubber body and driven with a pneumatic power.

In this paper, the structure and the fundamental characteristics of soft actuator and soft sensor are described, and then the structure and the fundamental operation of the developed soft hand are shown.
\end{abstract}

KEY WORDS

Soft robot hand, Soft mechanism, Pneumatics, Soft actuator, Soft tactile sensor

\section{INTRODUCTION}

For the coming advanced age society, there may not be enough working people in various åelds. Especially, in the high physical burden åeld such as medical welfare, agriculture and so on, the lack of working people may become a serious problem. In order to deal with such a situation, it is eãective to introduce a human friendly robot.

When robots work together with a human or contact with a human body directly in such as a medical welfare åeld, in order to avoid an accident from crash and so on, a cexibility is required for the robot $^{[1]}$.

In this study, to realize a robot which can work together with human or handle fragile objects, a soft robot hand constructed with a soft mechanism ${ }^{\text {[2][3] }}$ has been developed. The developed robot hand made of silicone rubber body and driven with a $p$ neumatic power .
A pneumatic soft mechanism provided with the çexibility owing to silicone rubber can easily achieve bending and torsion motions without joint, bearing and so on. Depending on the çexibility of the hand, this hand can accomplish almost the same motion as a human hand. Therefore, this hand can contact with a fragile object without complicated control method.

In this paper, the structures and the fundamental characteristics of soft mechanisms are described , and then the structure and the fundamental operation of the soft hand are shown.

\section{PNEUMATIC SOFT MECHANISM \\ ROTARY-TYPE SOFT ACTUATOR}

Fig. 1 shows a structure of the developed actuator. This actuator consists of a silicone rubber ball with an outer diameter of $12[\mathrm{~mm}]$, an inner diam- 
eter of $10[\mathrm{~mm}]$ and a silicone rubber bar with an outer diameter of $10[\mathrm{~mm}]$. The silicone rubber ball is made by forming a liquid silicone rubber with a metal mold. A rotary-type soft actuator of which the ball and the bar are covered with a äber tube. This åber tube is made from polyester åber tube as shown in Fig.1(b). The bended side of actuator is reinforced with aber to inhibit expanding in the axial direction. Therefore, when the compressed air is supplied into the actuator, it bends in only the circumferential direction without expanding in the axial direction as shown in Fig. 2.

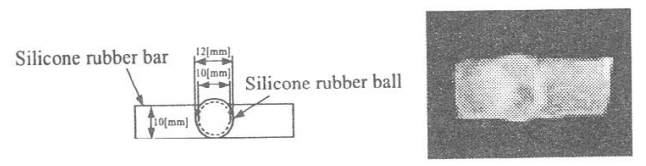

(a) Silicone rubber

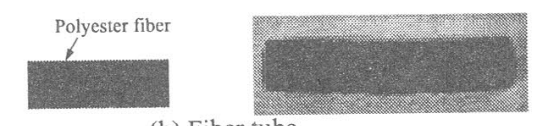

(b) Fiber tube

(c) Rotary-type soft actuator

Fig.1: Structure of rotary-type soft actuator

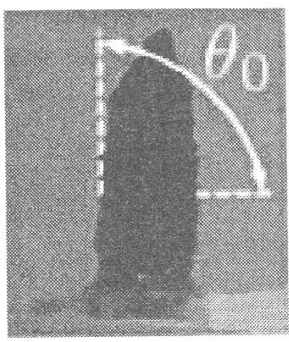

(a) Initial state

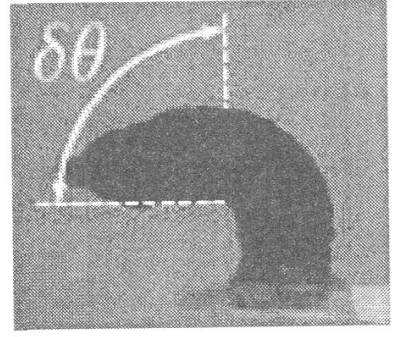

(b) Pressurized state
Fig.2: Operation of rotary-type soft actuator

Fig. 3 shows the relation between the inner pressure and the bending angle. The change of the angle becomes small over $300[\mathrm{kPa}$, , because the extention of the silicone rubber gradually nears the elastic limit. Enough large bending angle can be obtained.

\section{AIR MUSCLE}

To realize components for more complicated motion such as the root of thumb, the small size air muscle is developed. Since deformation of mechanism (bending, torsion) can be realized by the small

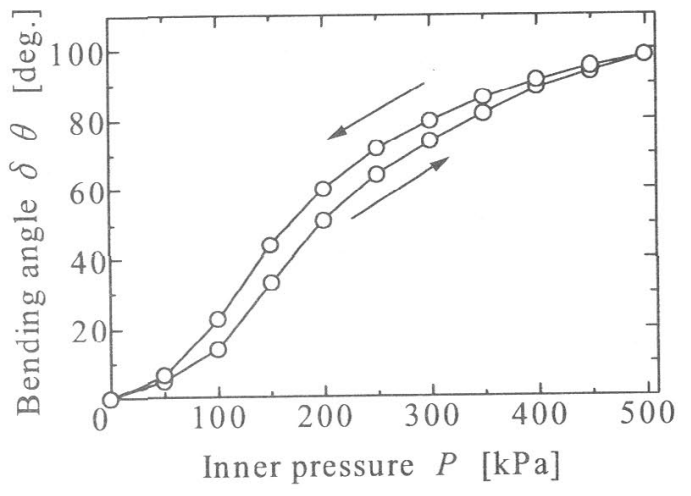

Fig.3: Relation between $\mathrm{P}$ and éí

sized air muscle easily, many kinds of complicated motions become possible.

In the following, the structure and the fundamental property of this actuator is described.

Fig. 4 shows the structure of the air muscle. It consists of silicone rubber tube (outer diameter 4[m$\mathrm{m}]$, inner diameter $3[\mathrm{~mm}]$ ). The tube is reinforced with polyester ăbers.

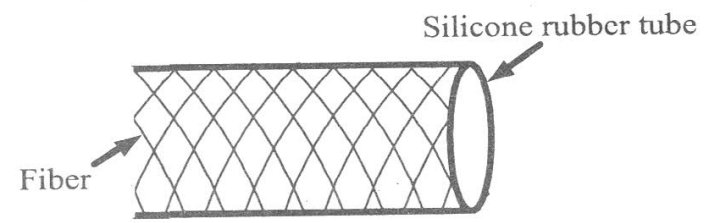

Fig. 4: Structure of air muscle

Fig.5(a) shows the initial state of the developed air muscle. When the compressed air is supplied to the air muscle, it contracts in the axial direction as shown in Fig.5(b).

Three kinds of air muscles $\left.\left(I_{0}=40,70,95 \mathrm{~mm}\right]\right)$ have been experimentally examined. $I_{0}$ is the initial length of the air muscle. The displacement when the compressed air is supplied to the air muscle from $0[\mathrm{kPa}]$ to $500[\mathrm{kPa}]$ at $50[\mathrm{kPa}$ interval is measured. Fig. 6 shows the relations between the inner pressure and the displacement. The experimental results show that the displacement saturates with an increase in the inner pressure. The elastic limit of silicone rubber causes this saturation.

The relation between the inner pressure and the contraction force of the air muscle is measured. The actuator is axed at the initial length in the measurement. The experimental result shown in Fig.7, it proves that the contraction force increases with an 


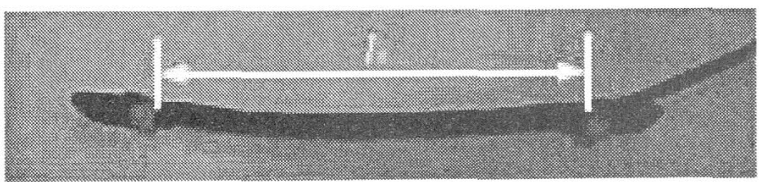

(a) Initial state

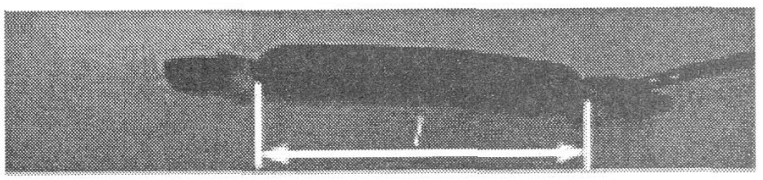

(b) Pressurized state

Fig.5: Operation of air muscle

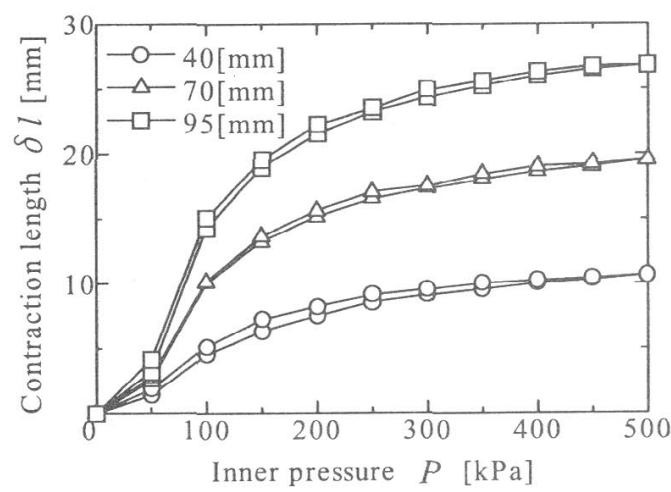

Fig.6: Relation between $P$ and $A$

increase in the length of the air muscle.

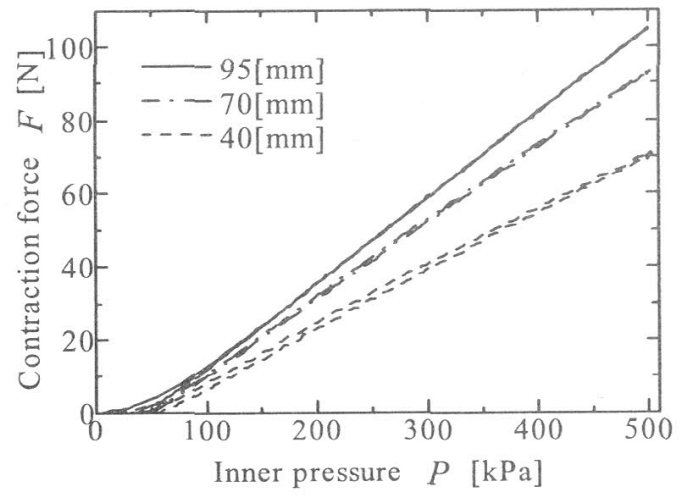

Fig.7: Relation between $P$ and $F$

The relations between the contraction ratio and the contraction force of each air muscle are shown in Fig.8. In the measurement, the arxed distance of the air muscle is decreased at $\mathrm{\theta}=\mathrm{I}_{0}=0.5$ intervals at the constant inner pressure of $500[\mathrm{kPa}$. It is shown that the contraction force decreases almost linearly along with an increase in the contraction ratio.

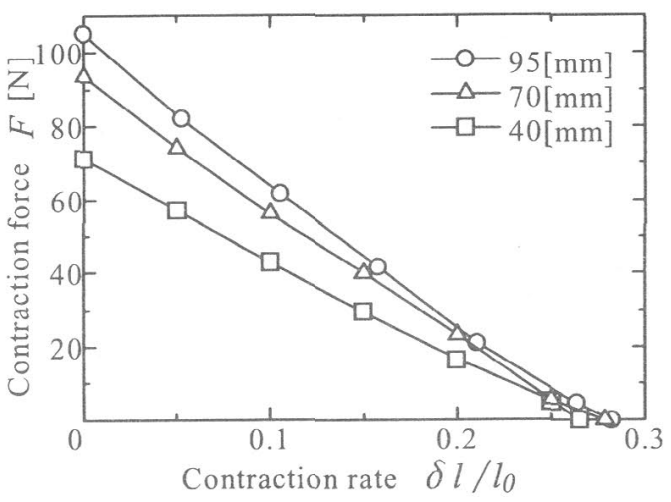

Fig.8: Relation between $\frac{\mathrm{e}}{\mathrm{l}_{\mathrm{o}}}$ and $\mathrm{F}$

\section{TACTILE SOFT SENSOR}

Sensors used in the soft hand should be provided with the çexibility to keep the softness of the mechanism. For this purpose, the pressure measurement type tactile soft sensor is developed. Fig. 9 shows the developed tactile sensor.

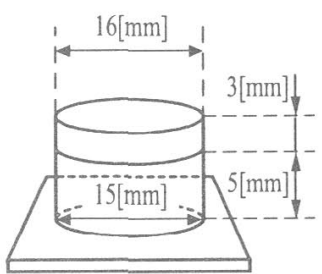

(a) Structure

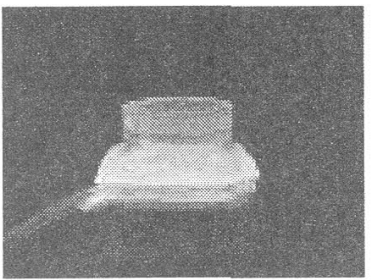

(b) Outlook
Fig.9: Tactile soft sensor

This sensor consists of cylindrical silicone rubber with an outer diameter $16[\mathrm{~mm}]$, inner diameter $15[\mathrm{~mm}]$. The cylindrical silicone rubber is made by forming a liquid silicone rubber with a metal mold.

Fig.10(a) shows the initial state of the sensor. When the external force is applied to it, the inner pressure of the sensor increases according to the deformation of cylindrical silicone rubber as shown in Fig.10(b). A tactile information can be detected by measuring the inner pressure change with a pressure sensor.

Fig.11 shows the relation between the applied external force and the inner pressure of the sensor. It is diécult for this sensor to detect the applied force smaller than 1.0[N], where the inner pressure is very small. Almost linear relation is obtained over $1.0[\mathrm{~N}]$. 


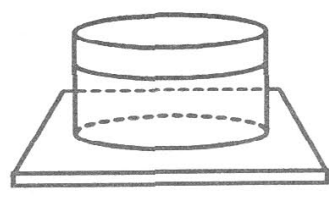

(a) Initial state

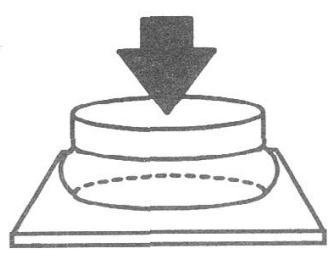

(b) Force applied state
Fig.10: Principle of tactile soft sensor

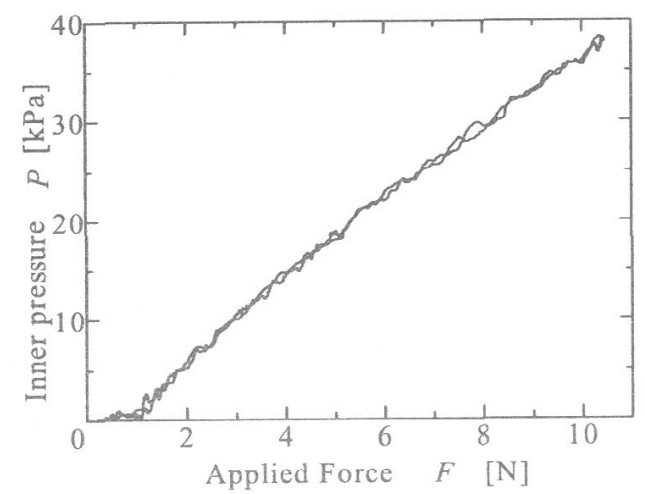

Fig.11: Relation between $F$ and $P$

\section{SOFT HAND}

\section{FUNDAMENTAL OPERATION}

Fig. 12 shows the structure and the outlook of the soft hand. This soft hand consists of the soft anger and the air muscle. The mass of hand is $900[\mathrm{~g}]$. The length is $185[\mathrm{~mm}]$. It has the same size as human. The soft anger has three joints as shown in Fig.13. The rotary-type soft actuators are put in position at intervals of $25[\mathrm{~mm}]$. The disposition of the air muscle is decided by referring the human muscle. This hand can operate almost same as a human hand as shown in Fig.14.

The scene when the hand grasps three kinds of objects is shown in Fig.15. The grasping objects are a soft ball with an outer diameter of $90[\mathrm{~mm}]$ , a mass of $170[\mathrm{~g}]$, a cubical wood with a length of $50[\mathrm{~mm}]$, a mass of $75[\mathrm{~g}]$ and a balloon with an outer diameter of $95[\mathrm{~mm}]$, a mass of 2[g]. The common and constant inner pressures are applied to the actuator and the air muscle. The inner pressures are 400 and $150[\mathrm{kPa}$, respectively. This hand can grasp objects with various characteristics such as a shape and a weight, depending on the çexibility of the mechanism.

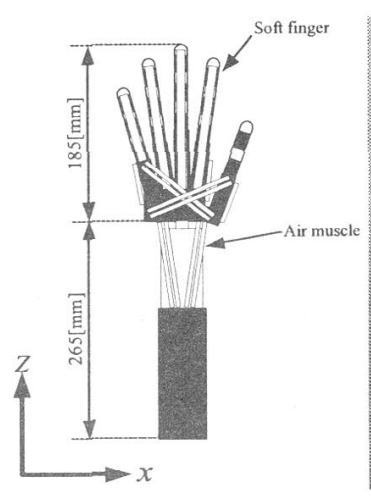

(a) Structure

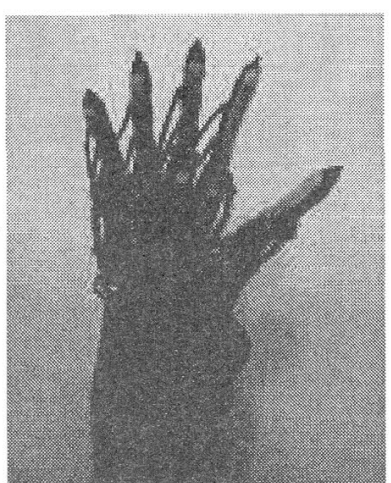

(b) Outlook
Fig. 12: Soft hand

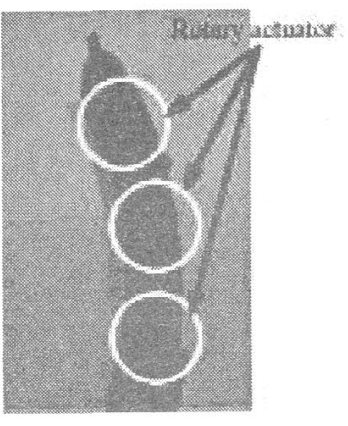

(a) Initial state

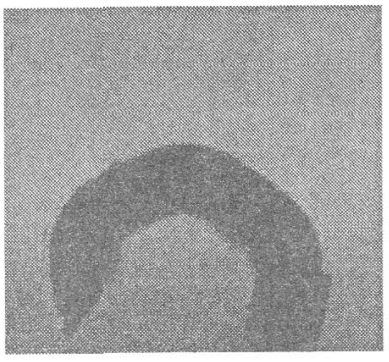

(b) Pressurized state
Fig.13: Outlook of soft ånger

\section{CONTACT MOTION}

By installing tactile soft sensor at the top of the anger, the soft hand can detect contact force. In the following, the contact motion with a constant force is discussed.

This hand contacts with a soft ball and a balloon at the constant force as shown in Fig.16.

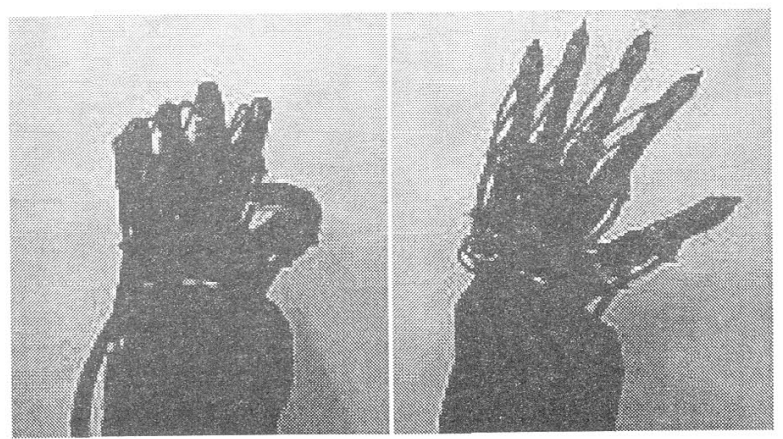

Fig.14: Fundamental operation of soft hand 


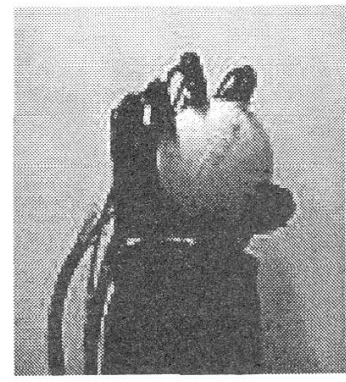

Softball

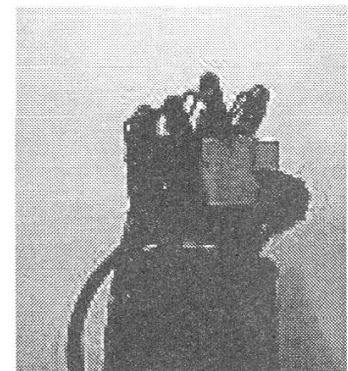

Cubical wood

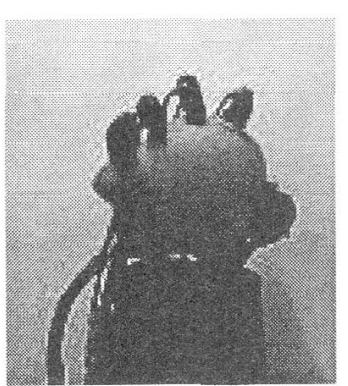

Balloon

Fig.15: Scene of grasping motion

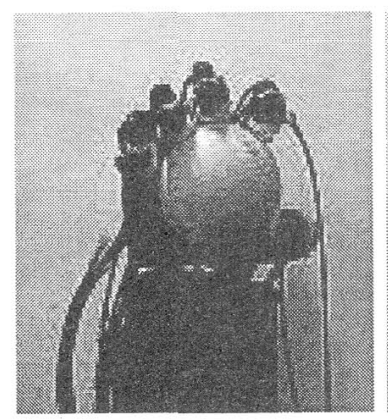

Softball

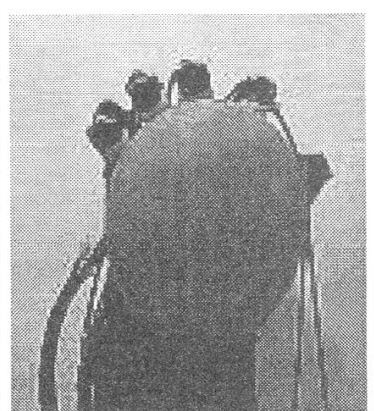

Balloon
Fig.16: Scene of contact motion

In the experiment, the inner pressure of the rotary actuator is deåned by the force control system as shown in Fig.17. The inner pressure of the air muscle is constant value. $\mathrm{F}_{r}, \mathrm{P}_{r}$ represent the desired contact force and the reference inner pressure of the rotary actuator, respectively. F , P represent the measured values of the rotary actuator. $F, P$ are detected by the tactile soft sensor and the pressure sensor. C represents $\mathrm{PI}$ controller. In the case of the softball and the balloon, the inner pressures of the air muscle are 150 and $50[\mathrm{kPa}]$, respectively.

Fig. 18 shows the experimental results of contact motion. The desired contact force $F_{r}$ is 1.0,1.5,2.0[N]. In the case of the softball, the little anger can not contact with the object, then the little anger is not used in this experiment. As shown in the ågures , this hand can contact with a objects with various characteristics, depending on detecting contac$t$ force. Especially, where this hand can contact with a softness object such as a balloon, this hand is eãective to contact with a fragile object.
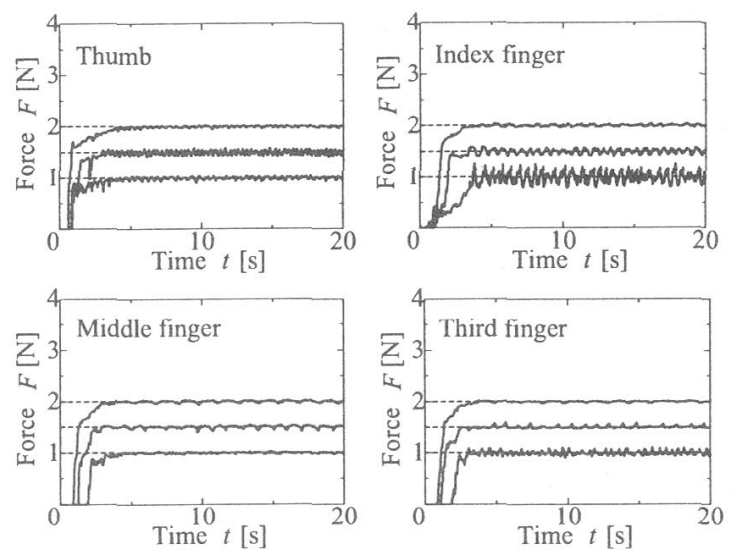

(a) Softball
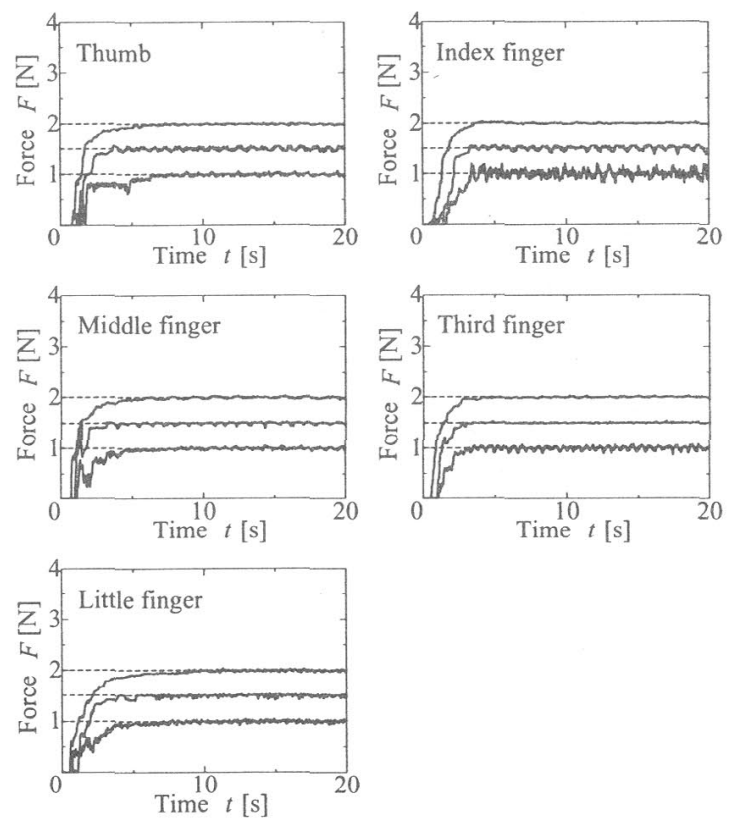

(b) Balloon

Fig.18: Contact motion with object

Fig. 19 shows the experimental results of contact motion when a vibration is applied to the softball in the $x$ axis direction. In the experiment, the vi- 


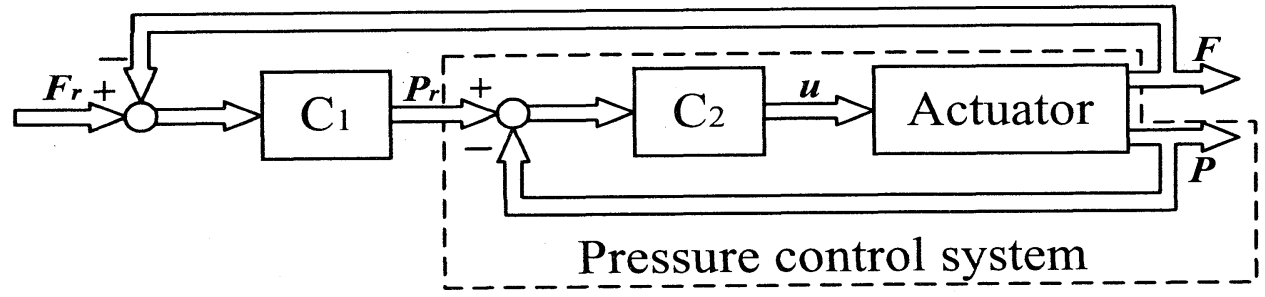

Fig.17: Force control system

bration with an amplitude of $2.5[\mathrm{~mm}]$, a frequency of $5[\mathrm{~Hz}]$ starts at $10[\mathrm{~s}]$. When the vibration is applied to the object, the contact forces agree with the desired contact force. From the results mentioned above, when the external force is applied to this hand, this hand can grasp objects certainly too.
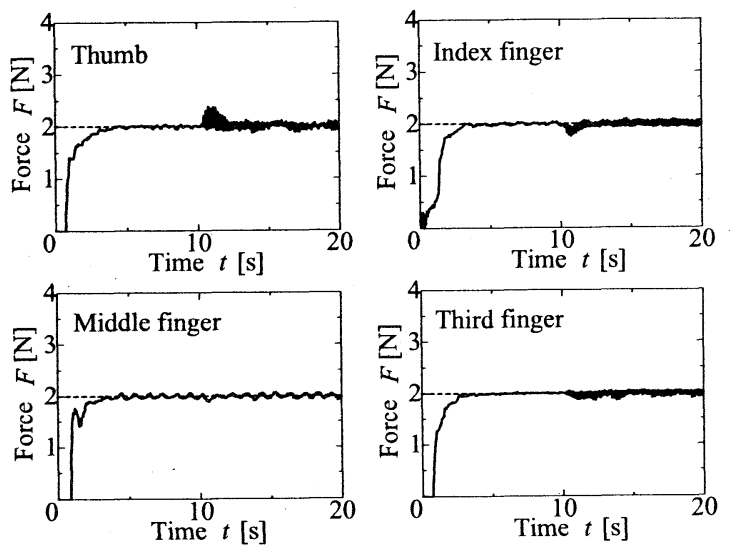

Fig.19: Contact motion with softball

\section{CONCLUSION}

In the paper, the structures and the fundamental characteristics of soft mechanisms have been described, and then the structure and the fundamental operation of the soft hand have been described.

By applying the çexibility to the hand, the hand can operate almost same as a human hand.

When a robot contacts with a fragile object such as a human body or fruits, a robot is required a delicate motion. In this case, the soft hand is eãective because this hand with a cexibility can contact with a fragile object without complicated control method.

The next subject of the study is to apply to grasping the delicate object such as a human body or fruits and so on.

\section{REFERENCES}

[1] Y.K.Lee,I.Shimoyama \A Skeletal Framework Artiåcial Hand Actuated by Pneumatic Artiå cial Muscles", Proc. of Int. Conf. on Robotics and Automation, pp.926\{931, 1999.

[2] T.Noritsugu,D.Kaneshiro and T.Inoue : $\backslash$ Soft Planar Actuator using Pneumatic-Rubber Balls", Journal of Robotics and Mechatronics, Vol.12, No.3, pp.254\{260, 2000.

[3] T.Noritsugu,M.Kubota and S.Yosimatsu : \Development of Pneumatic Rotary Soft Actuator Made of Silicone Rubber", Journal of Robotics and Mechatronics, Vol.13, No.1, pp.17\{22, 2001. 